\title{
Criação de funcionalidades no ROODA: um foco nos aspectos socioafetivos em ambientes virtuais de aprendizagem
}

\author{
Jacqueline Mayumi Akazaki ${ }^{1}$, Carla Adriana Barvinski' ${ }^{1}$, , Gislaine Rossetti \\ Madureira Ferreira1, Ana Carolina Ribeiro Ribeiro' ${ }^{1}$, Magalí Teresinha Longhi', \\ Leticia Rocha Machado', ${ }^{3}$, Patricia Alejandra Behar ${ }^{1}$
}

1Programa de Pós-Graduação em Informática na Educação - Universidade Federal do Rio Grande do Sul (UFRGS) - Porto Alegre, RS - Brasil

${ }^{2}$ Faculdade de Ciências Exatas e Tecnologia - Universidade Federal da Grande Dourados (UFGD) - Dourados, MS - Brasil

3Programa de Pós-Graduação em Tecnologias da Informação e Comunicação Universidade Federal de Santa Catarina (UFSC) - Araranguá, SC - Brasil

\{jacquelineakazaki, carlabarvinski, gislaine.coordena, carolribeiro2, leticiarmachado\}@gmail.com, magali.longhi@ufrgs.br, pbehar@terra.com.br

\begin{abstract}
This article presents the importance of considering the social and affective dimensions that occur in Distance Learning. Thus, we intend to develop four functionalities for the Virtual Learning Environment of the Cooperative Learning Network (VLECLN) which are the socio-affective combination, the pedagogical strategies recommendation system, the pedagogical model and the socio-affective map. As a result, it is expected that by providing VLECLN with new features, it will be possible to create pedagogical practices more sensitive to the student profile.

Resumo. O presente artigo apresenta a importância de considerar as dimensões sociais e afetivas que ocorrem no Ensino a Distância. Desse modo, pretende-se desenvolver quatro funcionalidades para o Ambiente Virtual de Aprendizagem da Rede Cooperativa De Aprendizagem (ROODA) que são a combinação socioafetiva, o sistema de recomendação de estratégias pedagógicas, o modelo pedagógico e o mapa socioafetivo. Como resultados, espera-se que ao dotar o ROODA de novas funcionalidades, seja possível criar práticas pedagógicas mais sensíveis ao perfil do estudante.
\end{abstract}

\section{Introdução}

$\mathrm{Na}$ Educação a Distância (EaD) o afastamento físico entre os atores do processo educacional tornam suas relações singulares. Diante disso, as formas de conhecer o outro, comunicar e atuar em um Ambiente Virtual de Aprendizagem (AVA) são elementos de análise para uma contínua qualificação dessa modalidade de ensino (ABED, 2018). Dada as particularidades da EaD, parte-se do pressuposto de que não deve relegar ao segundo plano ou mesmo desconsiderar a influência das relações sociais e afetivas sobre o processo de construção do conhecimento.

Este trabalho parte de uma reflexão sobre os aspectos sociais e afetivos evidenciados em AVA. Dessa forma, aborda-se a utilização da Rede cOOperativa De 
VIII Congresso Brasileiro de Informática na Educação (CBIE 2019)

Anais do VIII Workshop de Desafios da Computação aplicada à Educação (DesafIE 2019)

Aprendizagem (ROODA) para analisar as formas de interação e comunicação dos alunos. O AVA ROODA começou a ser elaborado no ano de 2000 pelo Núcleo de Tecnologia Digital Aplicada à Educação da Universidade Federal do Rio Grande do Sul (NUTED/ UFRGS). O ambiente possui seis funcionalidades que proporcionam espaços para interação, comunicação e compartilhamento de materiais, que são: Bate-papo, Biblioteca, Contatos, Diário de Bordo, Fórum e Webfólio. A partir de dados extraídos dessas ferramentas e um amplo referencial teórico Longhi (2011) elaborou o Mapa Afetivo, responsável por mapear os estado de ânimo de alunos no AVA. Por outro lado, a abordagem de sociogramas proposto por Moreno (1972) associado com princípios de Teoria dos Grafos, permitiu a criação do Mapa Social (LONGHI et al., 2014), que propicia o acompanhamento das interações sociais dos alunos no ambiente virtual. Desse modo, com base nesses dois recursos, propõe-se a construção de funcionalidades baseadas nos aspectos sociais e afetivos manifestados pelo aluno no ROODA.

\section{Contextualização}

$\mathrm{Na}$ valorização de uma formação mais integral, a Educação passa de forma incisiva a contemplar as dimensões sociais e afetivas. Dessa forma, acredita-se que a posse de tais informações pode fornecer ao professor elementos essenciais para suprir as demandas de seus alunos. Assim, com o intuito de potencializar as relações que ocorrem nos processos de ensino e aprendizagem, compreender os interesses e as necessidades dos alunos, e aproximar os atores envolvidos, surgiu a necessidade de uma análise das interações realizadas nestes espaços (BARVINSKI et al., 2019).

Nesse sentido, os Mapas Afetivo (MA) e Social (MS), ambas as funcionalidades do AVA ROODA, podem fornecer informações sobre os aspectos socioafetivos dos alunos. O ROODA que tem como objetivo proporcionar um espaço de interação entre seus participantes. Os mapas obtêm dados das seis funcionalidades do ambiente. O MA e o MS são ferramentas utilizadas exclusivamente pelo professor para visualizar graficamente os aspectos sociais e afetivos manifestados pelos estudantes participantes do AVA ROODA (LONGHI, 2011 e BEHAR, 2019).

A presente pesquisa tem como objetivo desenvolver quatro funcionalidades no ROODA que são a combinação socioafetiva, o sistema de recomendação de estratégias pedagógicas, o modelo pedagógico e o mapa socioafetivo. A combinação socioafetiva utilizará os traços de personalidade do Big Five obtidas junto ao Portal Personalitatem, recurso presente no Mapa Afetivo, e no Mapa Social, através do qual será possível realizar a formação de grupos de alunos. O sistema de recomendação, a partir dos estados socioafetivos dos estudantes advindo dos mapas e do Big Five, fornecerá estratégias pedagógicas para o professor. O modelo pedagógico terá como foco os dados fornecidos pelo Mapa Social. Para isso, será construído um Modelo Pedagógico com foco nas interações sociais no ambiente. O mapa socioafetivo, a partir dos aspectos sociais e afetivos, irá agregar as diferentes informações e gerar automaticamente, por meio de técnicas de Learning Analytics, um relatório sobre cada aluno 


\section{Resultados Esperados}

Espera-se que, com o desenvolvimento das quatro funcionalidades propostas para o ROODA, o professor possa refletir sobre os processos de mediação determinantes para o engajamento e a realização das aulas, ao aplicar estratégias e tomar decisões em prol do estudante atendendo seus interesses e necessidades individuais, almejando contribuir com o processo de construção do conhecimento. Acredita-se poder contribuir de maneira significativa aos processos de ensino e aprendizagem realizados com o suporte de diferentes tecnologias. Sabe-se que a Educação a Distância (EaD), apresenta acentuada expansão no Brasil e em todo o mundo. A possibilidade de estudo a domicílio, o respeito ao tempo e ao estilo de aprendizagem do aluno faz com que muitos aspirantes ao Ensino Superior optem por essa modalidade.

No entanto, ela apresenta uma organização diferente das que os alunos possuem na escola, exigindo uma atuação mais autônoma e expressiva. A falta desses aspectos faz com que os alunos, muitas vezes, se sintam desmotivados e sem confiança para a continuidade de seus estudos. Dessa forma, as taxas de evasão costumam ser, ainda, significativas. Entende-se, assim, que embora as ferramentas sejam constantemente aprimoradas, proporcionando o aperfeiçoamento da $\mathrm{EaD}$, há questões que ainda necessitam de maior atenção nesta modalidade de ensino, como o reconhecimento das manifestações afetivas dos alunos e as interações que emergem, ou não, nesses espaços.

\section{Referências}

Abed (2018). "Associação Brasileira de Educação a Distância. Informações do Anuário Brasileiro Estatístico de Educação Aberta e a Distância (Abraead/2017)", http://www.abed.org.br/site/pt/midiateca/noticias_ead/1526/2018/04qualidade_na_ed ucacao_superior_a_distancia_no_brasil_onde_estamos,_para_onde_vamos, December.

Barvinski, C., Ferreira, G., Machado, L., Longhi M. and Behar, P. (2019). "Construction of a Socio-affective Profile Model of Students in a Virtual Learning Environment". In Smart Education and e-Learning, Springer, Singapore, p. 159-168.

Behar, P. A. e colaboradores (2019). Recomendação Pedagógica em Educação a Distância. Porto Alegre, Penso Editora.

Longhi, M. T. (2011). "Mapeamento de aspectos afetivos em um ambiente virtual de aprendizagem". Tese de Doutorado (Doutorado em Informática na Educação), Centro Interdisciplinar de Informática na Educação. Universidade Federal do Rio Grande do Sul, Porto Alegre.

Longhi, M. T.; Machado. L, R,; Ribeiro, A. C. R. and Behar, P. A. (2014). "Mapa Social: Ferramenta Sociométrica para Mapear as Interações Sociais na Educação a Distância”. In VI Congreso Internacional sobre Aplicación de Tecnologías de la Información y Comunicaciones Avanzadas, Espanha, p. 377-384.

Moreno, J. L.; Bouza, J. G. e Karsz, S. (1972). Fundamentos de la Sociometria, Buenos Aires: Paidós. 